\title{
EDUCAÇÃO SEXUAL NO ENSINO FUNDAMENTAL: O TRABALHO COM ALUNOS DO $9^{\circ}$ ANO
}

\section{SEXUAL EDUCATION IN ELEMENTARY SCHOOL: THE WORK WITH STUDENTS IN $9^{\text {TH }}$ GRADE}

\author{
Rayane Priscila Silva* \\ Adda Daniela Lima Figueiredo*
}

\begin{abstract}
Resumo: A sexualidade faz parte da vida de todas as pessoas e especificamente na adolescência acontece de maneira muito diferenciada e peculiar. Este trabalho objetivou promover a adolescentes, discentes do $9^{\circ}$ ano do ensino fundamental de uma escola pública de Anápolis, a aquisição de conhecimentos sobre sexualidade, através da educação sexual. O estudo pautou sua revisão bibliográfica nos autores Abramovay et al. (2004), Biscoli (2005), Brandão e Heilborn (2006), Torres et al. (2008), Brêtas (2009), Junqueira (2009), dentre outros. Trata-se de uma pesquisa de abordagem qualitativa que utilizou para coleta de informação um questionário semiestruturado, aplicado em dois momentos, antes e após o trabalho com os adolescentes. Foram ministradas 11 aulas, totalizando 15 horas de atividade. $\mathrm{O}$ grupo de estudo foi formado por adolescentes com idade entre 13 e 17 anos. A maioria dos adolescentes $(83,3 \%)$ conversa sobre assuntos relacionados à sexualidade com amigos e obtém informações na mídia (55,5\%); 17\% dos adolescentes afirmaram que já tiveram a primeira relação sexual; destes, apenas 5,5\% usaram preservativo. Os métodos contraceptivos mais citados no pré-teste foram camisinha $(72,2 \%)$ e pílula anticoncepcional (33,3\%). No pós-teste houve uma variedade na citação de métodos. Verificouse com o pré-teste que as únicas doenças sexualmente transmissíveis citadas foram AIDS, sífilis e gonorreia. $\mathrm{O}$ trabalho comprovou que a realização de atividades de educação sexual com turmas de $9^{\circ}$ ano, em especial, de forma contínua, contribui para um desenvolvimento sexual saudável e a utilização do conhecimento para proteção pelos adolescentes.
\end{abstract}

Palavras-chave: Respeito ao corpo. Saúde. Sexualidade.

Abstract: The sexuality is part of every person's life specifically in the teenager stage and it happens in peculiar and different ways. This work promotes for teenagers, of the $9^{\text {th }}$ grade of fundamental public school in Anápolis, the acquisition of knowledge about sexuality that comes with sexual education. The study was made after biographies and authors: Abramovay et al. (2004); Biscoli (2005); Brandão e Heilborn (2006); Brêtas (2009); Foucault (1988); Junqueira (2009); Torres et al. (2008); Suplicy et al. (2000), and others too. The research has a qualitative approach that was used to collect information, with a structured questionnaire, given twice, before and after working with teenagers in 11 classes, total 15 hours of activities. The group was formed by teenagers in ages between 13 and 17 years old. The majority of teenagers $(83,3 \%)$ talk about subjects related to sexuality with their friends and get media information (55,5\%). $17 \%$ of teenagers conform that they had sexual intercourse, only 5,5\%

\footnotetext{
* Licenciada em Ciências Biológicas pela Universidade Estadual de Goiás. E-mail: <ray_prix@hotmail.com>

** Doutoranda em Educação pela PUC-GO. Professora da Universidade Estadual de Goiás. E-mail: <addadani@ hotmail.com>
} 
used condoms. The contraceptive methods that were mentioned more was the condoms (72, 2\%) and the birth control pills (33,3\%). On the second part of the test a variety of methods were mentioned. On the pre-test the only sexually transmitted diseases mentioned were AIDS, syphilis and gonorrhea. The work confirmed the need for sexual education activities with groups of the $9^{\text {th }}$ grade, in particular, continuously, contributing to a healthy sexual development and application of knowledge to protect the teenagers.

Key-words: Respect to the body. Health. Sexuality. Anápolis-GO.

\section{A sexualidade na adolescência e na escola - aprender o conhecimento científico}

De acordo com a Organização Mundial da Saúde (OMS, 2010), a adolescência é definida como a idade que corresponde dos 10 aos 19 anos. Trata-se de uma fase de transição que é caracterizada por transformações biológicas, como a passagem das características sexuais secundárias para a maturidade sexual, por mudanças nos padrões psicológicos e pela perda relativa da total dependência do indivíduo, buscando definir a função social que lhe é determinada pelos padrões culturais do contexto onde ele está inserido (ABRAMOVAY et al., 2004; LIMA, 2007).

Corroborando esses autores, Varela (2008) afirma que a adolescência é um período marcado por várias modificações, em que a pessoa passará por maturação física e psicológica. Ocorrerão, nesse período, significativas mudanças tanto fisicamente como no comportamento do adolescente.

Segundo dados do último censo do IBGE (2010), no Brasil há quase 34 milhões de adolescentes, o que corresponde a aproximadamente $18 \%$ da população total. É nessa fase que os indivíduos se encontram em situação de aprendizagem, possibilitando a adoção de novos comportamentos (CAMARGO; BOTELHO, 2007).

Asexualidade faz parte da vida de todas as pessoas e, especificamentena adolescência, acontece de maneira muito diferenciada, com características peculiares (ALMEIDA; CENTA, 2009). Apesar do avanço nos estudos sobre sexualidade humana, esse tema ainda é tratado com preconceitos e contradições, a ponto de muitos afirmarem que é um assunto que só deve ser discutido entre adultos (GIR et al., 2000).

Os adolescentes, quando não são bem informados, podem aprender e divulgar informações erradas ou inadequadas, as quais, somadas ao comportamento onipotente característico dessa fase, contribuem para experiências sexuais com riscos (COSTA et al., 2001).

A percepção do jovem se desenvolve a partir de suas diversificadas experiências cotidianas, na família, na escola, entre os amigos e no que é divulgado pela mídia. Assim, considerando a condição de vulnerabilidade a que o adolescente está exposto frequentemente, é preciso levar em conta a enorme responsabilidade que esses ambientes têm (TORRES et al., 2007).

A vulnerabilidade coletada junto a jovens no campo da sexualidade é registrada por Abramovay et al. (2004) em diferentes indicadores, como casos de desconhecimento sobre os ciclos reprodutivos, aborto e não uso de preservativos, podendo comprometer 
o processo de construção de identidade e a vivência da sexualidade. Nota-se, entretanto, quando o assunto é sexualidade, que a "ignorância” e qualidades consideradas "problemáticas" dos adolescentes - como a impulsividade, a adrenalina, o correr riscos - estimulam a sua criatividade e curiosidade.

Estudos indicam que a sexualidade é um tema que incita interesse, atenção e debates, tendo prioridade para os adolescentes, mas é preciso conhecer o que eles pensam, os mitos e tabus a respeito de sua sexualidade, a realidade deles, para que se possa abordar o assunto de modo que contribua para um desenvolvimento sexual saudável (CANO et al., 2000; ABRAMOVAY et al., 2004). Também, é importante conduzir os adolescentes à reflexão, negociando com eles a utilização do conhecimento para sua proteção (JARDIM; BRÊTAS, 2006).

Se o intuito que se tem em vista é o de informar, ou melhor, formar, a escola destaca-se por ser essa a sua principal função (SAITO; LEAL, 2000). É nesse ambiente que o indivíduo passa grande parte do seu tempo, tratando-se de um dos principais locais para contatos interpessoais (COSTA et al., 2001). A educação sexual na escola está sugerida nos Parâmetros Curriculares Nacionais, dando autonomia aos estabelecimentos de ensino para decidirem a melhor forma de abordar a temática (BRASIL, 1997).

A escola tem, portanto, muito a ver com essa temática, a qual, ampliada, correlaciona-se com matérias típicas do ambiente, especialmente nas áreas do conhecimento, do pensamento crítico, da ética, da comunicação e linguagem (ABRAMOVAY et al., 2004). Em seu trabalho de educação sexual, a instituição deve abordar diversas e diferentes opiniões, crenças e valores, auxiliando o jovem discente na sua reflexão, considerando o que ele julgar mais importante para construir sua autorreferência. O objetivo da escola não é o de substituir o que foi aprendido pelos jovens em sua família, mas sim de passar informações complementares, preenchendo lacunas nas informações que o jovem já possui (BISCOLI et al., 2005).

A educação sexual é um processo formal, organizado sistematicamente, que exige planejamento e deve ser proposto com responsabilidade e compromisso. Um trabalho que deverá problematizar, levantar questionamentos, proporcionando informações atualizadas e explicitando os diversos valores associados à sexualidade, para que os adolescentes possam tomar decisões e fazer escolhas adequadas (BACCO JUNIOR, 2009).

Segundo Santos (2001), vários são os motivos que justificam o trabalho de educação sexual na escola. Muitas famílias, por exemplo, não conversam sobre o assunto em casa, deixando a função para a instituição de ensino. O jovem, muitas vezes, acaba recebendo informações incompletas, erradas e preconceituosas de amigos ou da mídia. A escola torna-se, portanto, um espaço privilegiado para que os adolescentes possam expor seus questionamentos acerca da sexualidade (MOIZÉS; BUENO, 2010).

A aquisição de conhecimentos colabora para minimizar posturas erradas e inadequadas e para a prevenção de problemas (GIR et al., 2000). Alguns autores concluíram que o fato de os jovens terem aulas sobre sexualidade não os influenciou na decisão de iniciar a atividade sexual, porém usaram preservativos em maior escala na primeira relação e diminuiu o número de gestantes adolescentes (SAITO; LEAL, 2000). Em escolas que realizam um trabalho bem feito de educação sexual, alguns resultados importantes são apontados, como o aumento do rendimento escolar, devido ao alívio de tensão e preocupação com questões da sexualidade, e o 
aumento da solidariedade e respeito entre os estudantes (BACCO JUNIOR, 2009).

Mediante o exposto e baseado em referenciais teórico-práticos sobre o tema abordado, o trabalho ora apresentado objetivou compreender o conhecimento dos adolescentes do $9^{\circ}$ ano do ensino fundamental de uma escola pública de Anápolis-GO sobre sua sexualidade, principais curiosidades e fragilidades. Nesse sentido, a pesquisa buscou responder às seguintes questões norteadoras:

1. O que os adolescentes sabem sobre doenças sexualmente transmissíveis, gravidez, aborto, abuso sexual, métodos contraceptivos e aparelho reprodutor humano?

2. Qual a postura assumida pelos adolescentes nas relações de gênero?

\section{A pesquisa em uma escola pública - preparando o campo}

A pesquisa ocorreu com alunos do $9^{\circ}$ ano, do turno matutino do ensino fundamental de um colégio da rede pública na cidade de Anápolis-GO, localizado no bairro Jundiaí. A instituição funciona desde 1973 e atende, atualmente, 353 estudantes, do $6^{\circ}$ ano do ensino fundamental ao $3^{\circ}$ ano do ensino médio. $\mathrm{O}$ ensino fundamental funciona em período integral, sendo esse um dos fatores que favoreceu a escolha desse colégio, visto que as atividades da pesquisa poderiam ser realizadas no contraturno.

Como todo processo educativo, este estudo foi organizado e realizado a partir de revisão bibliográfica e aprofundamento teórico sobre a temática abordada. Trata-se de uma pesquisa de abordagem qualitativa que utilizou um questionário semiestruturado e gravações de todas as aulas como instrumentos de coleta de informações.
O questionário - cujo conteúdo era composto por dados pessoais; sexualidade e sexo; corpo: matriz da sexualidade; relações de gênero e doenças sexualmente transmissíveis - foi inicialmente testado e validado por professores e acadêmicos do curso de Ciências Biológicas da Universidade Estadual de Goiás.

Com os adolescentes, foi primeiramente aplicado o questionário (pré-teste), visando a caracterizar a população e obter dados sobre o conhecimento comum de seus componentes quanto ao tema sexualidade. Após a realização das oficinas com os discentes, foi aplicado o mesmo questionário (pós-teste) para identificar possíveis mudanças na estruturação do conhecimento dos respondentes.

Os encontros aconteceram nos meses de maio e junho de 2011, no período vespertino, com duração necessária para a realização de cada oficina (em torno de duas horas), conforme cronograma oportunizado pelo colégio. Atendendo aos preceitos éticos, participaram dos encontros todos os adolescentes que levaram assinado por seus responsáveis um “Termo de Aceite”, garantindo o anonimato e sua participação voluntária. Além disso, foi encaminhado aos pais um documento apresentando todos os temas a serem discutidos em sala.

A educação sexual na escola deve ser trabalhada de maneira sistematizada, proporcionando debates acerca da própria sexualidade e seus aspectos preventivos, de modo que os adolescentes sintam-se à vontade e falem sobre o assunto com confiança e liberdade (ALMEIDA, 2009). O uso de oficinas em projetos de sexualidade tem obtido bons resultados por tratar-se de uma metodologia de linha participativa, possibilitando discussões que privilegiam a troca de experiências. Tendo a dinâmica de grupo como suporte básico, assuntos difíceis podem 
ser falados sem expor os participantes em situações constrangedoras ou comprometedoras (ECOS, 2001).

Para que essa proposta fosse efetivada, o trabalho foi organizado em oficinas, estimulando a reflexão nos adolescentes, fornecendo informações, escutando e esclarecendo dúvidas. O diálogo foi sempre mantido com os jovens, por tratar-se de uma ferramenta básica no processo de educar para a sexualidade (MOIZÉS; BUENO, 2010).

Durante as oficinas os discentes eram organizados em círculo, procedimento esse que permitia a interação face a face e um bom contato visual entre todos os participantes. Para melhor compreensão dos adolescentes, na maioria das vezes a exposição do conteúdo teve como suporte o uso de material audiovisual, como slides e vídeos.

Para que o trabalho fosse efetuado sistematicamente, elaborou-se um roteiro especificando as oficinas, com seus temas organizados de acordo com os três eixos básicos determinados no PCN - Orientação Sexual, que são: 1) Corpo: matriz da sexualidade; 2) Relações de Gênero; e 3) Prevenção das DST/ AIDS. É importante destacar que os temas eram inicialmente flexíveis, podendo ser ou não abordados, dependendo da necessidade dos participantes. O roteiro não precisaria ser seguido de maneira rígida, caso houvesse indícios que demonstrassem a necessidade de mudanças.

As principais referências utilizadas para a organização das oficinas foram livros de Suplicy et al. (2000), Moore, K. L. et al. (2008) e Uzunian e Birner (2000); documentos disponíveis na internet, com acesso gratuito, do Ministério da Saúde (2006; 2008); dinâmicas de sexualidade da "Revista Adolescer”, da Associação Brasileira de Enfermagem; e sugestões de oficinas propostas pela organização não-governamental "Ecos - Comunicação em Sexualidade”.
Após a realização das oficinas e obtenção dos dados, estes foram analisados por estatística descritiva, parte da estatística que se preocupa com a organização e descrição dos dados experimentais, com o objetivo de tirar conclusões sobre populações com base nos resultados observados em amostras extraídas dessas populações (NETO, 2002). Os dados estão apresentados em porcentagem e dispostos em gráficos para melhor compreensão.

\section{O trabalho direcionado à educação sexual - a pesquisa em ebulição}

Após as reuniões com a direção e explicações aos pais, dezoito adolescentes colaboraram na realização deste trabalho, com total participação na aplicação do pré-teste. Todavia, no dia em que foi aplicado o pós-teste apenas $88,9 \%$ dos adolescentes estavam presentes e responderam ao questionário. Todos os adolescentes em ambos os testes (pré e pós) se declararam heterossexuais, com estado civil solteiro e sem filhos.

Identificou-se na população estudada a prevalência de alunos com faixa etária entre 13 e 14 anos (Figura 1), correspondendo à idade-série prevista na Lei de Diretrizes e Base da Educação de nosso país (BRASIL, 2006). Essa homogeneização na faixa etária foi um fator relevante para a realização da pesquisa, para a escolha das atividades e da forma como elas seriam organizadas e desenvolvidas, considerando que cada idade demonstra um tipo de interação particular entre o sujeito e o ambiente, com necessidades e interesses característicos e com sexualidade específica a cada etapa do desenvolvimento humano (COSTA et al., 2001; CRUZ; OLIVEIRA, 2002; DONIZETE, 2010). 
Figura 1 - Representatividade da idade dos adolescentes do $9^{\circ}$ ano do ensino fundamental de uma escola pública de Anápolis-GO - 2011.

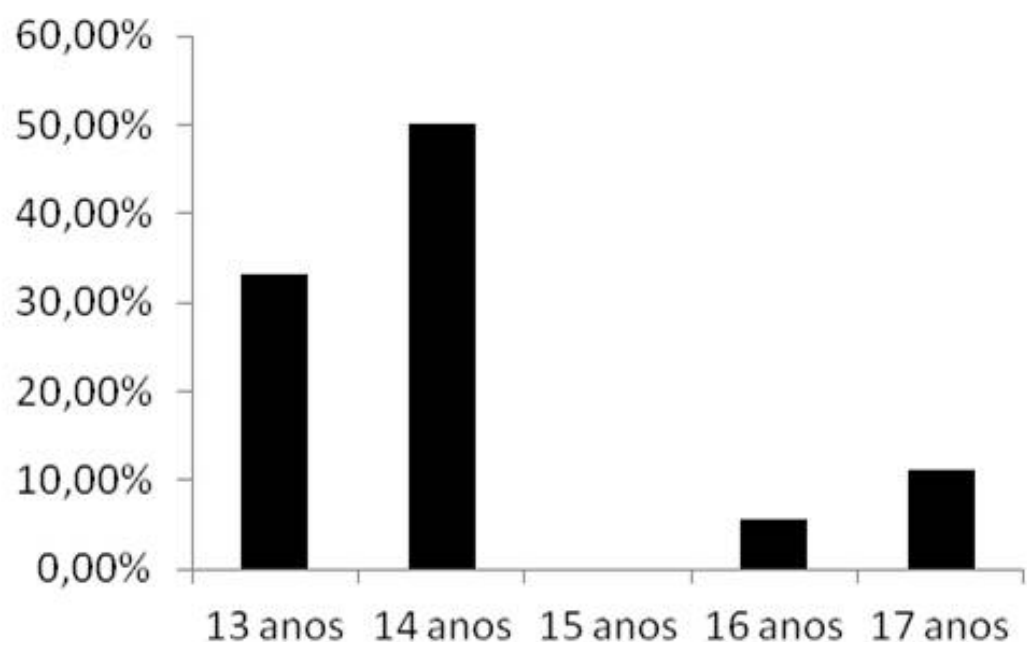

Fonte: Dados da pesquisa

Foram ministradas 11 aulas, que totalizaram 15 horas, com temas variados para atender às necessidades expostas no PCN de Orientação Sexual. Os temas foram: sexualidade; aparelho reprodutor humano; mudanças na adolescência; gravidez na adolescência; aborto; métodos contraceptivos; doenças sexualmente transmissíveis; abuso sexual; respeito pelo próximo.

Foi perceptível já no primeiro encontro o entusiasmo dos adolescentes. Fizeram muitas perguntas, principalmente os garotos, surgiram muitas risadas também; percebeu-se a vergonha de alguns para falar sobre o assunto e o desconhecimento de alguns termos como "métodos contraceptivos"; "sistema genital” e "abuso sexual”. Verificamos a utilização de um vocabulário mais popular para fazer referência ao pênis, à vagina ou ao ato de masturbação. Esse comportamento pode ser um demonstrativo do quanto o assunto é pouco discutido de modo mais sistemático e educativo, da necessidade e do interesse que os adolescentes têm para falar sobre sua sexualidade e sobre as mudanças corporais e psicológicas decorrentes dessa fase.

Quando questionados sobre suas fontes de pesquisa, verificou-se que uma parcela expressiva de adolescentes (83,3\%) conversa sobre assuntos relacionados à sexualidade/sexo/prevenção com amigos; 44,4\%, com pais e/ou demais familiares; e 22,2\%, com professores. Ainda, 55,5\% receberam de amigos a maior parte das informações que têm sobre sexualidade/sexo ou as obtiveram na mídia (programas de televisão, internet, revistas), e nenhum adolescente procura obter informações com um médico.

Dados semelhantes são encontrados nos trabalhos de Romero et al. (2007), Freitas e Dias (2010) e Moura et al. (2011). Esses autores afirmam que, muitas vezes, as conversas sobre sexualidade/sexo transitam na superficialidade, existindo desconfianças quanto à qualidade das informações obtidas. A alta procura por informações na mídia e com amigos propicia que os adolescentes 
apresentem déficit no conhecimento sobre as especificidades dos métodos contraceptivos, colocando-os em posição de risco frente às DST e gravidez não planejada (BIÉ; DIÓGENES; MOURA, 2006). Talvez o fato de esses adolescentes não procurarem um médico seja por não saberem, até então, que podem procurar serviço médico, gratuitamente, para tirar suas dúvidas sobre sexualidade, e que têm esse direito assegurado no Estatuto da Criança e do Adolescente, conforme o artigo 11, reformulado em 2005 (MINISTÉRIO DA SAÚDE, 2010).

Neste estudo, identificou-se que a faixa etária da iniciação sexual foi entre 11 e 13 anos; $17 \%$ dos adolescentes afirmaram que já tiveram a primeira relação sexual (Figura 2) e destes apenas 5,5\% usou preservativo, pertencendo ao sexo feminino. Segundo Freitas e Dias (2010), atualmente há uma mudança no comportamento sexual dos jovens, como a redução da idade em que iniciam as relações sexuais. Tem-se observado que a busca pela autonomia na sexualidade é cada vez mais precoce, implicando iniciação sexual, embora os adolescentes ainda não tenham entendimento necessário para se relacionarem sexualmente (BRANDÃO; HEILBORN, 2006).

Portanto, é de extrema importância que debates sobre sexualidade, gravidez e DST/AIDS sejam realizados, para que o adolescente tenha acesso a informações que favoreçam mudanças de atitude. Desse modo, a família, a escola e os serviços de saúde precisam desenvolver trabalhos para promoção da saúde sexual e reprodutiva do adolescente (MOURA et al., 2011). Os programas educacionais em saúde precisam ser implantados efetivamente, antes que os adolescentes se envolvam em comportamentos de risco. Além disso, há evidências de que a inclusão da educação sexual no currículo escolar contribui para que a iniciação sexual aconteça mais tardiamente (ROMERO et al., 2007).

Figura 2 - Porcentagem dos adolescentes do $9^{\circ}$ ano do ensino fundamental de uma escola pública de Anápolis-GO que alegam já terem tido relação sexual.

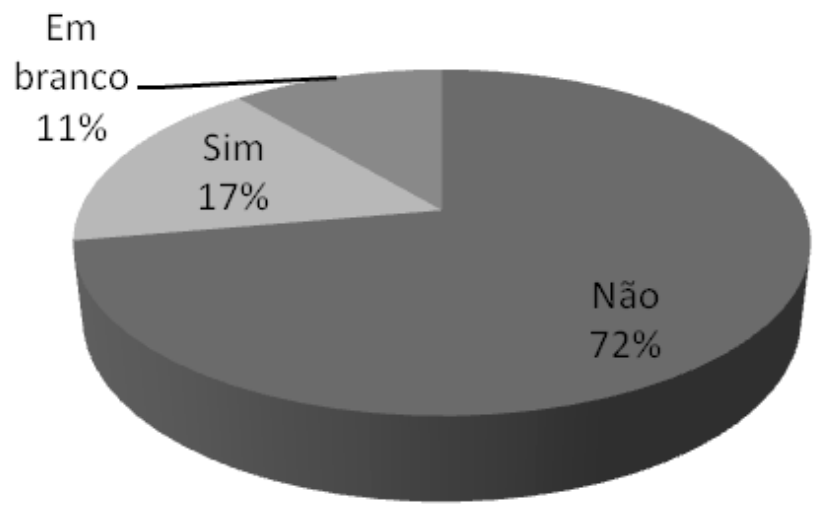

Fonte: Dados da pesquisa 
Sobre o período fértil do homem e da mulher, no pré-teste $66,7 \%$ dos adolescentes não souberam responder. No pós-teste, a questão deixou de ser respondida por 30,5\% deles, e $25 \%$ dos adolescentes do sexo masculino afirmaram que o homem está fértil todos os dias, não respondendo, porém, sobre o período fértil da mulher. Todas as adolescentes responderam a questão sobre o período fértil do homem, e $37,5 \%$ delas deram sua resposta sobre o período fértil da mulher, considerando que em um ciclo de 28 dias esse período ocorreria no $14^{\circ}$ dia após a menstruação, quando a mulher estivesse ovulando. Resultados como esses apontam o quanto é importante que os adolescentes sejam incentivados a conhecer o seu corpo e o do sexo oposto, para desenvolverem uma preocupação com o autocuidado e terem a capacidade de decisão sobre práticas sexuais seguras (CAMARGO; FERRARI, 2009).

A iniciação sexual precoce pode muitas vezes ser agravada pela falta de conhecimento, por exemplo, sobre o funcionamento do corpo e o período fértil, podendo resultar em uma gravidez inesperada. Há vários registros sobre as consequências de uma gravidez na adolescência, como a alta possibilidade de mortalidade materno-fetal, ocorrências de abortos, incidência de anemia, infecção urinária, baixo ganho de peso materno, parto prematuro, baixo peso do bebê, além de pouca cobertura pré-natal. Outras consequências que podem ocorrer são a evasão escolar e conflitos psicológicos frente à maternidade (GODINHO et al., 2000).

Os métodos contraceptivos mais citados no pré-teste foram a camisinha (72,2\%) e a pílula anticoncepcional (33,3\%), justamente os mais divulgados em campanhas governamentais e na mídia. No pós-teste esses métodos continuaram bastante citados, ocorrendo, porém, maior variedade na citação de métodos contraceptivos (Figura 3).
A anticoncepção é um tema muito importante, especialmente na adolescência, considerando-se o alto índice de gravidez e incidência de doenças sexualmente transmissíveis nessa fase. Conhecer os métodos contraceptivos, bem como a eficácia, a utilização correta de cada método e os riscos advindos de relações sexuais desprotegidas é fundamental para que os adolescentes possam se relacionar sexualmente de maneira adequada e saudável, assegurando a prevenção da gravidez inesperada e das DST/AIDS, além de possibilitar o direito do exercício da sexualidade desvinculado da procriação (VIEIRA et al., 2006). 
Figura 3 - Métodos contraceptivos citados pelos adolescentes do $9^{\circ}$ ano do ensino fundamental de uma escola pública de Anápolis-GO - 2011.

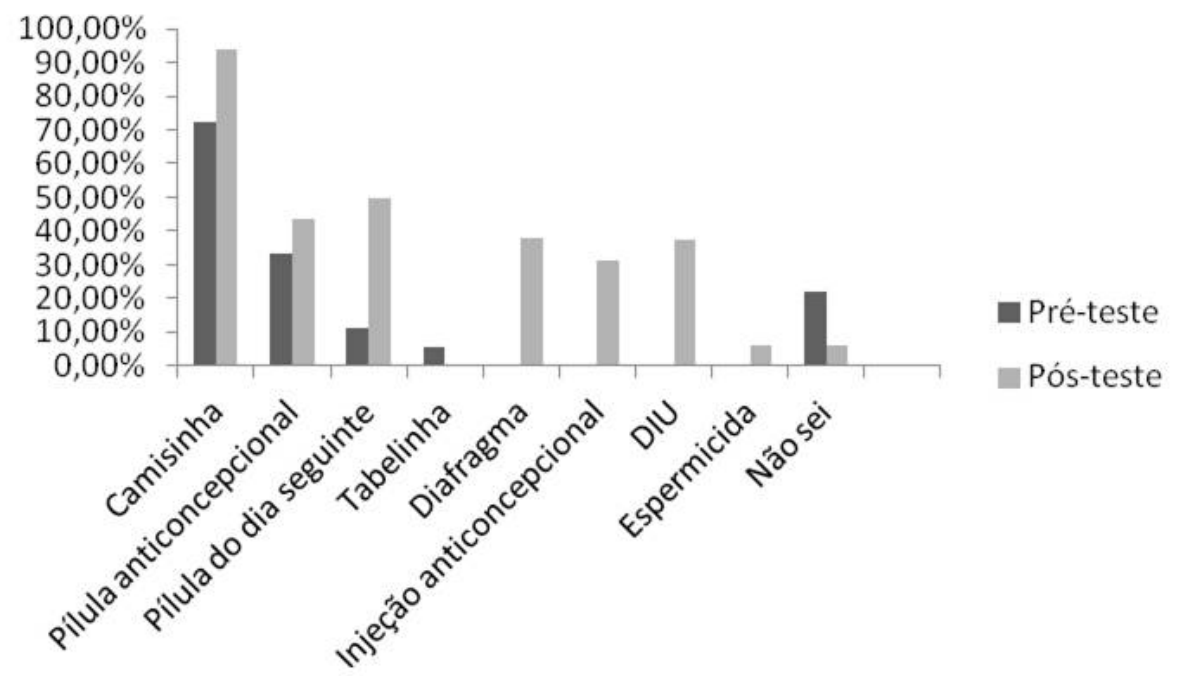

Fonte: Dados da pesquisa

A frase "Os meninos podem ter diversas relações sexuais na adolescência, já as meninas devem ser mais recatadas, ou seja, elas não podem querer fazer como os homens fazem, pois isso as desmoralizaria perante a sociedade." foi apresentada para que os discentes expressassem sua opinião. No pré-teste, 5,5\% dos adolescentes concordaram parcialmente com a afirmativa, 22,2\% não tinham opinião formada, $16,7 \%$ discordaram e $55,6 \%$ concordaram plenamente. No pós-teste, $12,4 \%$ ainda não tinham opinião formada, 6,2\% concordaram parcialmente com o conteúdo da frase, 37,4\% não concordaram e $44 \%$ continuaram concordando plenamente. Os comentários foram semelhantes em ambos os testes. Os adolescentes que concordaram plenamente com a afirmativa usaram os seguintes argumentos: "Eu concordo plenamente, se uma menina faz o mesmo que o homem ela fica mal falada.”; “... acaba com sua reputação." (alunas do sexo feminino); "Porque quando o homem pega muitas ele é chamado de pegador, já a mulher é chamada de galinha." (aluno do sexo masculino).
Resultados e argumentos como esses demonstram o quanto é difícil realizar mudanças em valores e pensamentos cultural e socialmente estabelecidos. As normas socioculturais em torno da temática sexualidade impõem às moças o recato em relação ao sexo, enquanto é esperado que os rapazes não tenham muito pudor; eles são estimulados a serem fortes e viris. Isso, por fim, dificulta o diálogo aberto sobre sexo e o compartilhamento de estratégias quanto à iniciação sexual (JEOLÁS; FERRARI, 2003; VILLELA; DORETO, 2006; GUBERT; MADUREIRA, 2008).

Quando questionados sobre o convívio e a aceitação de convívio com homossexuais, $66,7 \%$ dos adolescentes responderam que tratam os homossexuais e os heterossexuais da mesma maneira, conversando e convivendo normalmente com eles; já 22,2\% dos entrevistados, todos pertencendo ao sexo masculino, responderam que não tratam mal os homossexuais, mas não gostam de tê-los como amigos ou próximos a eles; e 11,1\% nunca se depararam com essa situação. 
Pesquisas revelam que é alta a expressão de ideias e atitudes de intolerância para com a homossexualidade entre estudantes no ambiente escolar, notadamente entre os rapazes. Apontam a necessidade de inclusão, no currículo escolar, da diversidade de orientação sexual como forma de combate à discriminação (CLAM, 2009; JUNQUEIRA, 2009). Na atualidade, a escola tem como uma de suas funções educar para a diversidade, demonstrando que a heterossexualidade não é a única manifestação possível da sexualidade humana, expondo os estudantes a contextos de relacionamento nos quais a diversidade e o respeito pelas diferenças são valorizados (ASINELLI-LUZ; CUNHA, 2011).

Os alunos foram questionados sobre o que entendiam por abuso sexual e $72,1 \%$ deles responderam, basicamente, que esse tipo de abuso é "Relação sexual sem consentimento dos dois."; "Uma pessoa adulta que pega criança menor de idade, abusa dela que não pode fazer nada."; "Quando uma pessoa força a outra a ter relações sexuais, contra a sua vontade." No pré-teste, 27,7\% dos adolescentes responderam que não sabiam o que é abuso sexual, sendo esse valor reduzido para $6,2 \%$ no pós-teste.

O abuso sexual é uma forma de violência que envolve poder, coação e/ou sedução, desigualdades de gênero e idade que podem incluir, além do ato sexual com ou sem penetração, carícias, manipulação da genitália, mama ou ânus, exploração sexual, voyeurismo, a pornografia e o exibicionismo, consistindo um mito a afirmativa de que o abuso sexual se limita ao estupro (ABRAPIA, 2002).

Trata-se de um problema que envolve, também, questões legais de proteção à vítima, punição do agressor e terapias de atenção à saúde física e psicológica decorrentes do abuso (ARAÚJO, 2002). Por isso, é importante que em um trabalho de educação sexual na escola seja abordado sistematicamente esse tema, para que os adolescentes sejam capazes de distinguir e reconhecer as formas de abuso sexual, conhecer as leis que os amparam, podendo agir e denunciar.

Ao serem questionados sobre as Doenças Sexualmente Transmissíveis (DST) conhecidas, verificou-se com o pré-teste que as únicas doenças sexualmente transmissíveis citadas pelos adolescentes foram AIDS, sífilis e gonorreia. Essas doenças continuaram citadas no pós-teste, aparecendo, porém, outras DST no relato dos adolescentes (Figura 4).

Comparando pré e pós-teste, pode-se observar o aumento da resposta "Não sei" dos adolescentes. Isso pode ser atribuído ao descaso que muitos têm para responder questionários, tornando-se muitas vezes mais fácil responder que não sabe. É preocupante, porém, o fato de $12,5 \%$ dos adolescentes afirmarem que não conheciam nenhuma DST, já que a adolescência é a fase que apresenta a maior incidência dessas doenças (BRÊTAS et al., 2009a). Tal fato confirma que, apesar de a maioria dos adolescentes buscarem informações sobre sexualidade, seus conhecimentos sobre doenças sexualmente transmissíveis ainda são insuficientes ou inadequados (ROMERO et al., 2007). 
Figura 4 - Apresentação das DST conhecidas pelos adolescentes do $9^{\circ}$ ano do ensino fundamental de uma escola pública de Anápolis-GO - 2011.

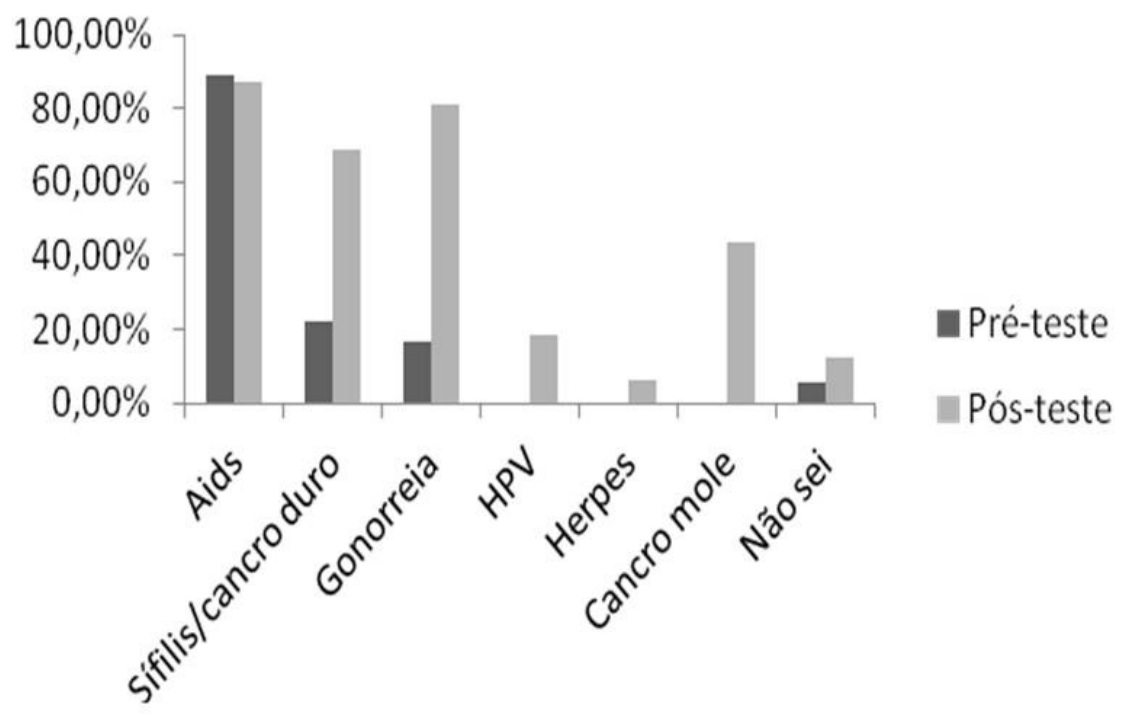

Fonte: Dados da pesquisa

Foi perguntado aos adolescentes como é possível prevenir uma DST, e o uso da camisinha foi citado pela maioria deles 77,8\% (pré-teste) e 87,5\% (pós-teste) - demonstrando um bom nível de conhecimento preventivo pelos adolescentes (Figura 5). No entanto, estudos possibilitaram a constatação de que a camisinha não é usada por todos e nem em todas as relações sexuais, apesar de os jovens conhecerem os riscos a que estão expostos, apontando a necessidade de definir estratégias para aumentar o uso contínuo do preservativo (TEIXEIRA et al., 2006; BRÊTAS et al., 2009b; OLIVEIRA et al., 2009).

Pequena parcela dos adolescentes, $11,1 \%$ no pré-teste e $6,2 \%$ no pós-teste, respondeu que é possível fazer a prevenção de uma DST escolhendo bem a parceira ou o parceiro. O fato de achar que conhece a parceira ou o parceiro faz com que o (a) adolescente acredite que não contrairá uma DST, colocando-se assim em situação de risco, já que algumas DST têm um período de latên- cia para o aparecimento de sintomas, não sendo perceptíveis no início, mas podendo ser transmitidas (BRÊTAS et al., 2009b).

Dos entrevistados, $11,1 \%$ no pré-teste e $12,5 \%$ no pós-teste responderam que se evita DST não compartilhando seringas. Esse valor é considerado baixo, já que o compartilhamento de seringas está entre os principais modos de transmissão do vírus causador da AIDS, que, por sua vez, é enquadrada como uma DST (MINISTÉRIO DA SAÚDE, 2011). Além disso, 16,6\% (pré-teste) dos adolescentes responderam que não sabiam como não contrair uma DST, diminuindo esse índice para 12,5\% no pós-teste. Apesar da pequena diferença percentual entre pré-teste e pós-teste, esses dados merecem atenção, pois é esperado que os adolescentes tenham conhecimento pelo menos do uso da camisinha como modo de prevenção de doenças sexualmente transmissíveis, devido à intensa divulgação dessa informação na mídia e em campanhas (OLIVEIRA et al., 2009). 
Figura 5 - Métodos possíveis para se prevenir uma DST, na concepção dos adolescentes do $9^{\circ}$ ano do ensino fundamental de uma escola pública de Anápolis-GO, 2011.

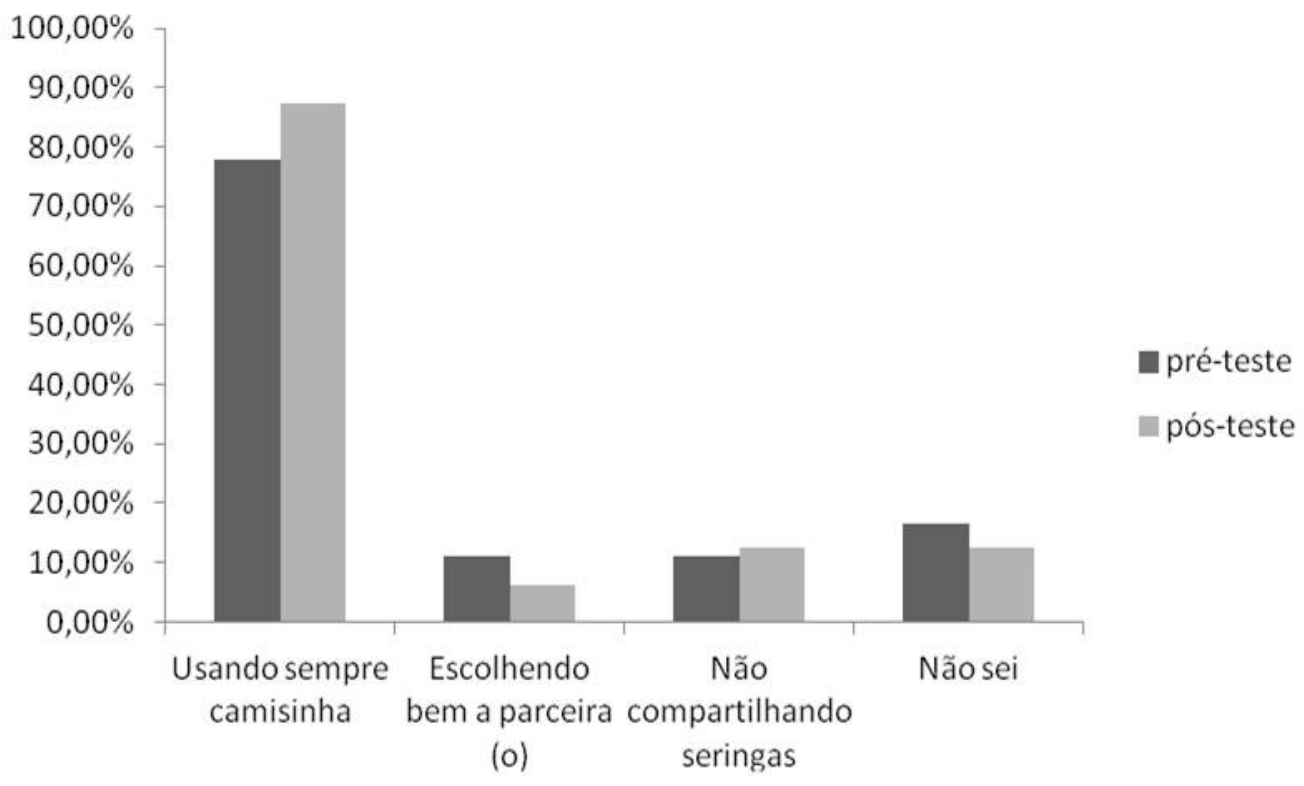

Fonte: Dados da pesquisa

Quanto à forma de transmissão ou prevenção de uma DST, 38,9\% dos adolescentes acreditam que se a mulher tomar a pílula do dia seguinte ou anticoncepcional, ela estará evitando ter uma DST; no pós-teste esse valor reduziu para 24,9\%. Já 50\% dos adolescentes responderam, no pré-teste, que as doenças sexualmente transmissíveis não são adquiridas através de sexo oral ou anal, reduzindo-se esse valor para 37,4\%, no pós-teste.

As doenças sexualmente transmissíveis são consideradas como fator importante que influencia de diferentes maneiras a saúde sexual e reprodutiva do adolescente. Esse desconhecimento de como uma DST é transmitida ou prevenida pode comprometer o processo natural de crescimento e desenvolvimento e levar o adolescente a comportamentos sexuais desprotegidos. Por isso, é importante que as instituições de ensino e de saúde, bem como as campanhas que estão envolvidas na educação sexual do adolescente, preocupem-se em transmitir o conhecimento, fazendo reforços periódicos dos ensinamentos, pois os adolescentes podem, muitas vezes, não estar com sua atenção voltada para a prevenção. Já ouviram falar da DST, mas não sabem como preveni-la (ROMERO et al., 2007).

Do total de entrevistados, 38,9\% afirmaram, no pré-teste, acreditar que uma pessoa saudável pode contrair AIDS se abraçar ou beijar um portador do vírus HIV ou sentar-se em um banco logo após o portador do vírus se levantar; no pós-teste, $12,4 \%$ desses entrevistados ainda continuavam acreditando em tal afirmação. Índices de 11,1\% (pré-teste) e 6,2\% (pós-teste) foram identificados como falsos pelos entrevistados ao se perguntar se uma pessoa usuária de drogas injetáveis, compartilhando agulhas e seringas, corre o risco de contrair o vírus da AIDS.

Ter conhecimentos sobre a AIDS é de grande importância para a prevenção da mesma, e embora seja enfatizado pela mídia 
como o vírus HIV pode ser transmitido, uma quantidade considerável de adolescentes desconhece as maneiras de não transmissão do vírus (CAMARGO; BOTELHO, 2007). Esse desconhecimento quanto à prevenção e transmissão pode, também, provocar preconceitos e atitudes desfavoráveis em relação aos que foram infectados pelo vírus (SEIDL; RIBEIRO; GALINKIN, 2010). Portanto, é imprescindível considerar que a AIDS está presente nas sociedades e que é indispensável o acesso da população ao conhecimento sobre essa doença, visando ao seu controle e prevenção, bem como ao respeito às pessoas portadoras do vírus HIV e à convivência com elas (CAMARGO; BARBARÁ; BERTOLDO, 2007; SEIDL; RIBEIRO; GALINKIN, 2010).

Mesmo que tenha ocorrido uma diminuição nas respostas erradas dos adolescentes, ainda se deve dar muita atenção às questões relativas à sexualidade, já que mesmo após o desenvolvimento do trabalho com eles, no total de 11 aulas, parte dos adolescentes continuou mantendo respostas equivocadas e preocupantes. Tal fato evidencia que trabalhar a mudança de comportamento que visa à vivência de uma sexualidade saudável, com o objetivo de reconstrução de atitudes responsáveis, significa uma árdua e demorada tarefa que necessita de intervenções frequentes (CAMARGO; FERRARI, 2009).

\section{A pesquisa em algumas linhas: consi- derações para futuros trabalhos com a mesma temática}

A realização de oficinas junto aos discentes do $9^{\circ}$ ano do Ensino Fundamental, utilizando a metodologia participativa e em grupo, possibilitou que os adolescentes interagissem entre eles e com a pesquisadora, expondo dúvidas, medos e vivências, trocando informações e experiências e, ao mesmo tempo, se divertindo.

Está confirmado que a escola é um lugar adequado para se trabalhar educação sexual, já que muitos adolescentes procuram informações sobre sexualidade, mas, muitas vezes, em fontes não confiáveis. Assim, organizando esse trabalho de maneira sistemática e sempre com embasamento teórico-científico, é possível que o educador contribua para a aquisição de conhecimentos corretos. Ao fazer isso, ele estará permitindo que os adolescentes aos poucos possam ir conhecendo seu corpo e o do outro, métodos de prevenção, tenham uma iniciação sexual segura e a vivência de sua sexualidade de maneira natural, comum ao desenvolvimento humano, e de modo saudável.

Mesmo em um prazo tão limitado de tempo, no trabalho realizado foi possível observar que os conhecimentos que os entrevistados adquiriram acerca do assunto provocaram mudanças no seu comportamento e nas expressões utilizadas cotidianamente. Tal fato permite concluir que a formação desses adolescentes foi adequadamente lapidada no decorrer da pesquisa e que trabalhos semelhantes devem ser implementados nas escolas ao longo de todo ano.

Apesar do número amostral limitado, é esperado que esta pesquisa possa servir como embasamento para outros trabalhos. Somente com pesquisas, trabalhos teórico-práticos com esse eixo temático é que será possível a otimização da educação sexual nas instituições de ensino brasileiras.

\section{Referências}

ABRAMOVAY, M.; CASTRO, M. G.; SILVA, L. B. Juventudes e sexualidade. Brasília: UNESCO Brasil, 426 p., 2004. 
ABRAPIA - Associação Brasileira Multiprofissional de Proteção à Infância e Adolescência. Abuso sexual: mitos e realidades. 3. ed. rev. amp. e atual. Editora Autores e Agentes e Associados, 2002. 45 p.

ALMEIDA, A. C. C. H.; CENTA, M. L. A família e a educação sexual dos filhos: implicações para a enfermagem. Acta Paul. Enferm. São Paulo, v. 22, n.1, p. 71-76, jan./ fev. 2009.

ALMEIDA, S. A. Orientação Sexual nas escolas: seria possível se não incomodasse? Dissertação (Mestrado em Enfermagem) Centro de Ciências da Saúde, Universidade Federal da Paraíba. João Pessoa, 2009. 103 p.

ARAÚJO, M. F. Violência e abuso sexual na família. Psicologia em Estudo. Maringá, v.7, n.2, p.3-11, jul./dez.2002.

ASINELLI-LUZ, A.; CUNHA, J. M. Percepções sobre a discriminação homofóbica entre concluintes do Ensino Médio no Brasil entre 2004 e 2008. Educar em Revista. Curitiba, n.39, p.87-102, jan./abr.2011.

BACCO JUNIOR, A. M. Breve olhar sobre sexualidade na fala dos professores da educação de jovens e adultos. Dissertação (Mestrado em Educação) - Faculdade de Ciências e Letras, Campus de Araraquara, Universidade Estadual Paulista, 2009. 181 p.

BIÉ,A.P.A.;DIÓGENES,M.A.R.; MOURA, E. R. F. Planejamento familiar: o que os adolescentes sabem sobre este assunto. Rev. Bras. em Promoção da Saúde. Fortaleza, v. 19, n. 3, p. 125-130, 2006.

BISCOLI, C.; FAVARÃO, N. L. R.; FEITEN, R. H.; SOUZA, A. C. P.; PERPÉTUO, C. L. Sexualidade em sala de aula: um estudo da produção de sentidos. Arq. Ciênc. Saúde Unipar. Umuarama, v. 9, n. 1, p. 47-55, jan./ mar. 2005.
BRANDÃO, E. R.; HEILBORN, M. L. Sexualidade e gravidez na adolescência entre jovens de camadas médias do Rio de Janeiro, Brasil. Cad. Saúde Pública. Rio de Janeiro, v. 22, n. 7, p. 1421-1430, 2006.

BRASIL. Secretaria de Educação Fundamental. Parâmetros Curriculares Nacionais: Orientação sexual. Brasília: MEC/ SEE, 1997. p. 285-336

. Ministério da Educação. Secretaria de Educação Básica. Ampliação do Ensino Fundamental para nove anos: $3^{\circ}$ relatório do programa. Brasília, 2006.

BRÊTAS, J.R.S.;OHARA, C.V.S.;JARDIM, D. P.; MUROYA, R. L. Conhecimento sobre DST/AIDS por estudantes adolescentes. Rev. Esc. Enferm. USP, v. 43, n. 3, p. 551557, 2009a.

BRÊTAS, J.R.S.;OHARA,C.V.S.;JARDIM, D. P.; MUROYA, R. L. Conhecimentos de adolescentes sobre doenças sexualmente transmissíveis: subsídios para prevenção. Acta Paul. Enferm. São Paulo, v. 22, n. 6, p. 786-792, 2009b.

CAMARGO, B. V.; BARBARÁ, A.; BERTOLDO, R. B. Concepção pragmática e científica dos adolescentes sobre a AIDS. Psicologia em Estudo. Maringá, v. 12, n. 2, p. 277-284, maio-ago., 2007.

.; BOTELHO, L. J. AIDS, sexualidade e atitudes de adolescentes sobre proteção contra o HIV. Rev. Saúde Pública [online], v. 41, n. 1, p. 61-68, 2007.

CAMARGO, E. Á. I.; FERRARI, R. A. P. Adolescentes: conhecimentos sobre sexualidade antes e após a participação em oficinas de prevenção. Ciência e Saúde Coletiva. v. 14, n. 3, p. 937-946, 2009.

CANO, M. A. T.; FERRIANI, M. G. C.; GOMES, R. Sexualidade na adolescência: um estudo bibliográfico. Rev. Latino-am. 
Enfermagem. Ribeirão Preto, v. 8, n. 2, p. 18-24, abr., 2000.

CLAM - Centro Latino-Americano em Sexualidade e Direitos Humanos- IMS/UERJ. Gênero e diversidade na escola: formação de professoras/es em gênero, Orientação Sexual e Relações Étnico-raciais. Livro de Conteúdo. Rio de Janeiro: CEPESC; Brasília: SPM, 266 p., 2009.

COSTA, M. C. O.; LOPES, C. P.A.; SOUZA, R. P.; PATEL, B. N. Sexualidade na adolescência: desenvolvimento, vivência e propostas de intervenção. Jornal de Pediatria. v. 77, supl.2, p. 217-224, 2001.

CRUZ, A. C. N.; OLIVEIRA, S. M. P. Sexualidade do adolescente: um novo olhar sem mitos e preconceitos. Belém: Universidade da Amazônia, 2002, 92p.

DONIZETE, N. L. Sexualidade infantil: um olhar pedagógico. Aparecida de Goiânia: Instituto Superior de Educação da Faculdade Alfredo Nasser, 2010, 23p.

ECOS - COMUNICAÇÃO EM SEXUALIDADE. Sexo sem vergonha: uma metodologia de trabalho com Educação Sexual. São Paulo: ECOS, 2001. Disponível em: <http:// www.adolec.br/bvs/adolec/P/textocompleto/ sexosemvergonha/indice.htm>. Acesso em: 12 fevereiro 2011.

FREITAS, K. R.; DIAS, S. M. Z. Percepções de adolescentes sobre sua sexualidade. Texto Contexto Enferm. Florianópolis, v. 19, n. 2, p. 351-357, abr-jun., 2010.

GIR, E.; NOGUEIRA, M. S.; PELÁ, N. T. R. Sexualidade humana na formação do enfermeiro. Rev. Latino-am. Enfermagem. Ribeirão Preto, v. 8, n. 2, p. 33-40, abr., 2000.

GODINHO, R. A.; SCHELP, J. R. B.; PARADA, C. M. G. L.; BERTONCELLO, N. M. F. Adolescentes e grávidas: onde buscam apoio? Rev. Latino-am. Enfermagem. Ribeirão Preto, v. 8, n.2, p. 25-32, abr. 2000.
GUBERT, D.; MADUREIRA, V. S. F. Iniciação sexual de homens adolescentes. Ciência e Saúde Coletiva, v. 13, supl. 2, p. 2247-2256, 2008.

IBGE. Instituto Brasileiro de Geografia e Estatística. Censo 2010 - pirâmide etária. Disponível em: <http://www.ibge.gov.br/censo2010/piramide_etaria/index.php> Acesso em: 13 janeiro 2011.

JARDIM, D. P.; BRÊTAS, J. R. S. Orientação sexual na escola: a concepção dos professores de Jandira-SP. Rev. Bras. Enferm. Brasília, v. 59, n. 2, p. 157-162, mar./abr., 2006.

JEOLÁS, L. S.; FERRARI, R. A. P. Oficinas de prevenção em um serviço de saúde para adolescentes: espaço de reflexão e de conhecimento compartilhado. Ciência e Saúde Coletiva. v. 8, n. 2, p. 611-620, 2003.

JUNQUEIRA, R. D. Diversidade sexual na educação: problematizações sobre a homofobia nas escolas. Brasília: UNESCO Brasil, 458 p., 2009.

LIMA, J. D. O despertar da sexualidade na adolescência. In: PEREIRA, J. L.; FANELLI, C.; PEREIRA, R. C.; RIOS, S. (Orgs.). Sexualidade na adolescência no novo milênio. Rio de Janeiro: Universidade Federal do Rio de Janeiro, Pró-reitoria de Extensão, p. 15, 2007.

MINISTÉRIO DA SAÚDE. Secretaria de Atenção em Saúde. Departamento de Ações Programáticas Estratégicas. Área Técnica de Saúde do Adolescente e do Jovem. Diretrizes nacionais para a atenção integral à saúde de adolescentes e jovens na promoção, proteção e recuperação da saúde. Brasília, 2010.

Secretaria de Vigilância em Saúde. Pesquisa de conhecimentos, atitudes e práticas na população brasileira de 15 a 64 anos- 2008. Brasília, 2011. 
MOIZÉS, J. S.; BUENO, S. M. V. Compreensão sobre sexualidade e sexo nas escolas segundo professores do ensino fundamental. Rev. Esc. Enferm. USP, São Paulo, v. 44, n. 1, p. 205-212, mar. 2010.

MOURA, L. N. B.; GOMES, K. R. O.; RODRIGUES, M. T. P.; OLIVEIRA, D. C. Informação sobre contracepção e sexualidade entre adolescentes que vivenciaram uma gravidez. Acta. Paul. Enferm. v. 24, n. 3, p. 320-326, 2011.

NETO, P. L. O. C. Estatítica descritiva. In: . Estatística. 2. ed. São Paulo: Edgard Blucher, 2002, p. 1-4.

OLIVEIRA, D. C.; PONTES, A. P. M.; GOMES, A. M. T.; RIBEIRO, M. C. M. Conhecimentos e práticas de adolescentes acerca das DST/HIV/AIDS em duas escolas públicas municipais do Rio de Janeiro. Esc Anna Nery Rev Enferm. v. 13, n. 4, p. 833841, out-dez., 2009.

OMS - Organização Mundial da SaúdeWorld Health Organization. Participant manual: IMAI One-day Orientation on Adolescents Living with HIV. (Section 2Adolescent Development, 15 p. Disponível em: $\quad<$ http://whqlibdoc.who.int/publications/2010/9789241598972_eng.pdf $>$ Acesso em: 13 janeiro 2011.

ROMERO, K. T.; MEDEIROS, E. H. G. R.; VITALLE, M. S. S.; WEHBA, J. O conhecimento das adolescentes sobre questões relacionadas ao sexo. Rev. Assoc. Med. Bras. São Paulo, v. 53, n. 1, p. 14-19, 2007.

SAITO, M. I.; LEAL, M. M. Educação sexual na escola. Pediatria. São Paulo, v. 22, n. 1, p.44-48, 2000.

SANTOS, M. A. Orientação Sexual no $1^{\circ}$ e $2^{\circ}$ ciclos do Ensino Fundamental: uma realidade distante? Caicó: Universidade Federal do Rio Grande do Norte, 2001, 60 p.
SEIDL, E. M. F.; RIBEIRO, T. R. A.; GALINKIN, A. L. Opiniões de jovens universitários sobre pessoas com HIV/AIDS: um estudo exploratório sobre preconceito. Psico - USF. v. 15, n.1, p.103-112, jan-abr. 2010.

TEIXEIRA, A. M. F. B.; KNAUTH, D. R.; FACHEL, J. M. G.; LEAL, A. F. Adolescentes e uso de preservativos: as escolhas dos jovens de três capitais brasileiras na iniciação e na última relação sexual. Cad. Saúde Pública. Rio de Janeiro, v. 22, n. 7, p. 13851396, jul., 2006.

TORRES, C. A.; BESERRA, E. P.; BARROSO, M. G. T. Relações de gênero e vulnerabilidade às doenças sexualmente transmissíveis: percepções sobre a sexualidade dos adolescentes. Esc. Anna Nery R. Enferm. Rio de Janeiro, v. 11, n. 2, p. 296302, jun., 2007.

VARELA, D. A. S. Programa de Educação Sexual IST/HIV/SIDA com adolescentes de uma escola secundária de Cabo Verde: percepção dos atores envolvidos no programa. Dissertação (Mestrado em Saúde coletiva) - Instituto de Saúde Coletiva, Universidade Federal da Bahia. Salvador, 161 p., 2008.

VIEIRA, L. M.; SAES, S. O.; DÓRIA, A. P. B.; GOLDBERG, T. B. L. Reflexões sobre a anticoncepção na adolescência no Brasil. Rev. Bras. Saúde Matern. Infant. Recife, v.6, n.1, p.135-140, jan./mar., 2006.

VILLELA, W. V.; DORETO, D. T. Sobre a experiência sexual dos jovens. Cad. Saúde Pública. Rio de Janeiro, v. 22, n. 11, p. 24672472, nov., 2006. 